\title{
Green-based Biosynthesis of Zinc Oxide Nanoparticles Using Clitoria Ternatea Flower Extract and Its Antibacterial Activity
}

\author{
Selvaraj Prabhu ${ }^{1,2}$, Daniel Thangadurai Thangaian ${ }^{3}$, Palaniswamy Vijai Bharathy ${ }^{4}$ \\ ${ }^{1}$ Department of Research and Development, Bharathiar University, Tamil Nadu, India. \\ ${ }^{2}$ Department of Physics, Hindusthan College of Engineering and Technology, Coimbatore, Tamil Nadu, India. \\ ${ }^{3}$ Department of Nanoscience and Technology, Sri Ramakrishna Engineering College, Coimbatore, Tamil Nadu, India. \\ ${ }^{4}$ Department of Physics, C.B.M College, Coimbatore, Tamil Nadu, India. \\ $\square$ Corresponding author. E-mail: prabhucsa@gmail.com; Phone: +91-6383619588
}

Received: Jul.7, 202I; Accepted: Nov. 4, 2021; Published: Dec. 10, 202I

Citation: Selvaraj Prabhu, Daniel Thangadurai Thangaian, and Palaniswamy Vijai Bharathy, Green-based Biosynthesis of Zinc Oxide Nanoparticles Using Clitoria Ternatea Flower Extract and Its Antibacterial Activity. Nano Biomed. Eng., 202 I, I3(4): 394-400.

DOI: 10.5101/nbe.v13i4.p394-400.

\begin{abstract}
The present study reports the biosynthesis of zinc oxide nanoparticles (ZnO NPs) using Clitoria ternatea flower extract and examination of their antibacterial activity. The change in color of the reaction mixture from violet to yellow colour indicated the formation of $\mathrm{ZnO}$ NPs. The formation of $\mathrm{ZnO}$ NPs was confirmed by the appearance of a maximum absorption peak at $381 \mathrm{~nm}$ in the UVvisible spectrum. The XRD pattern corresponding with the JCPDS card for $\mathrm{ZnO}$ showed the presence of purecrystalline $\mathrm{ZnO}$ NPs. FTIR spectra confirmed the stretching vibrations of $\mathrm{C}=\mathrm{O}, \mathrm{C}-\mathrm{O}-\mathrm{H}$, and $\mathrm{O}-\mathrm{H}$ groups involved in the reduction of $\mathrm{ZnO}$ NPs. The size and morphology of the $\mathrm{ZnO}$ NPs were confirmed by Transmission Electron Microscopy (TEM). Further particle size was determined by using Dynamic Light Scattering (DLS). Furthermore, the antibacterial activity of ZnO NPs showed significant inhibitory activity against Escherichia coli and Staphylococcus aureus bacteria.
\end{abstract}

Keywords: Biosynthesis, Zinc oxide nanoparticles, Characterization, XRD, Antibacterial activity

\section{Introduction}

Nowadays, the biosynthesis of metal oxide (MO) nanomaterials has received a lot of attention due to their significant properties such as physical, chemical, biological, mechanical, optical and magnetic properties [1]. These characteristic properties make MOs nanomaterials ideal for diverse applications in the field of material science, electronics, medicine, agriculture, environmental, textile and food processing [2]. Among various $\mathrm{MOs}, \mathrm{ZnO}$ is a wide band gap n-type semiconductor $(3.37 \mathrm{eV}$ ) with a hexagonal wurtzite crystal structure, mainly an inorganic compound, and high excitation binding energy (60 meV) exhibits unique properties such as catalytic, chemical, nonlinearoptical, biocompatibility, bacterial resistivity, and UV filtering properties [3]. The controllable size, surface volume, crystalline nature and morphological properties of ZnO NPs have enabled their use in various applications such as ceramics, gas sensor, solar cells, cosmetics, ferromagnetism, food supplements, cosmetics and antibacterial efficacies [4-6]. Different methods have been reported for the synthesis of $\mathrm{ZnO}$ NPs such as coprecipitation [7], hydrothermal [8], solgel [9], electrochemical [10], solvothermal [11], and microwave assisted [12]. However, these methods 
are prone to various disadvantages such as expensive reagents, hazardous solvents and high energy and time consuming. Alternatively, biosynthesis is a simple, less toxic, safe, cost effective, eco-friendly and high yield method. The biosynthesis of ZnO NPs using various plants such as Aloe vera [13], Moringa oleifera [14], Tectona Grandis [15], Couroupita guianensis [16], Hibiscus subdariffa [17], Cassia fistula[18], Atrocarpus gomezianus [19] and Vitex trifolia [20] has already been reported.

The Clitoria ternatea is a long-used traditional medicinal plant belonging to the family Fabaceae and known under the common name Butterfly pea. Clitoria ternatea has been used to treat several diseases such as diabetics, cancer, inflammation fever, skin diseases, eye and throat infection, liver disease and urinary disorder [21]. The flower extract of Clitoria ternatea contains valuable bioactive compounds such as anthocyanin, flavonoids, phenols, alkaloids, and glycosides that have the ability to act as a good antimicrobial agent and can be employed as a capping and reducing agent for the formation of $\mathrm{ZnO}$ NPs [22]. Hence, the present study was aimed at eco-friendly biosynthesis of ZnO NPs using aqueous flower extract of Clitoria ternatea and evaluation their antibacterial activity against $E$. coli and $S$. aureus bacteria.

\section{Experimental}

\section{Materials}

Analytical grade of Zinc nitrate hexa hydrate [ $\mathrm{Zn}$ $\left.\left(\mathrm{NO}_{3}\right)_{2} \cdot 6 \mathrm{H}_{2} \mathrm{O}\right]$ were purchased from Merck. Deionized water was used as solvent throughout the biosynthesis process. Fresh flowers of Clitoria Ternatea (F) were collected from local region in Coimbatore district,
Tamil Nadu, India.

\section{Preparation of the flower extract}

The Clitoria ternatea flowers were washed first with tap water, followed by deionized water $(3 \times 25 \mathrm{~mL})$ to remove the external dust particles and allowed to dry in the open air. $10 \mathrm{~g}$ of the dried flowers chopped into small pieces was taken in a glass beaker along with $100 \mathrm{~mL}$ of deionized water and boiled at $80^{\circ} \mathrm{C}$ for 30 min. The colour of the aqueous solution changed to dark blue. The prepared extract was cooled to room temperature and was filtered using No. 1 Whatman filter paper. The extract was stored at $4{ }^{\circ} \mathrm{C}$ for further use.

\section{Synthesis of the ZnO-NPs}

$40 \mathrm{~mL}$ of $0.1 \mathrm{M}$ solution of $\mathrm{Zn}\left(\mathrm{NO}_{3}\right)_{2} \cdot 6 \mathrm{H}_{2} \mathrm{O}$ was added to $10 \mathrm{~mL}$ of the undiluted flower extract (10 wt\%) of Clitoria ternatea. The solution mixture was maintained under constant stirring at $60{ }^{\circ} \mathrm{C}$ for $2 \mathrm{~h}$. The colour of the solution changed from violet to yellow followed by precipitation, thus confirming the formation of ZnO NPs. The solution was centrifuged at $7500 \mathrm{rpm}$ for $15 \mathrm{~min}$ to separate the nanoparticles which were then washed with distilled water and dried at $80{ }^{\circ} \mathrm{C}$ for $4 \mathrm{~h}$ followed by calcinations at $400{ }^{\circ} \mathrm{C}$ for $2 \mathrm{~h}$ in a muffle furnace. The calcinated ZnO NPs were powdered by using an alloy mortar and pestle for further characterization. The schematic representation of the biosynthesis steps for ZnO NPs is shown in Fig. 1.

\section{Antibacterial activity studies}

Antibacterial activity of the biosynthesized ZnO NPs was studied by well diffusion method. The bacterial suspensions of $E$. coli and $S$. aureus were swabbed in Muller Hinton agar plates with sterile cotton swabs and were allowed to dry for 10 minutes before placing the

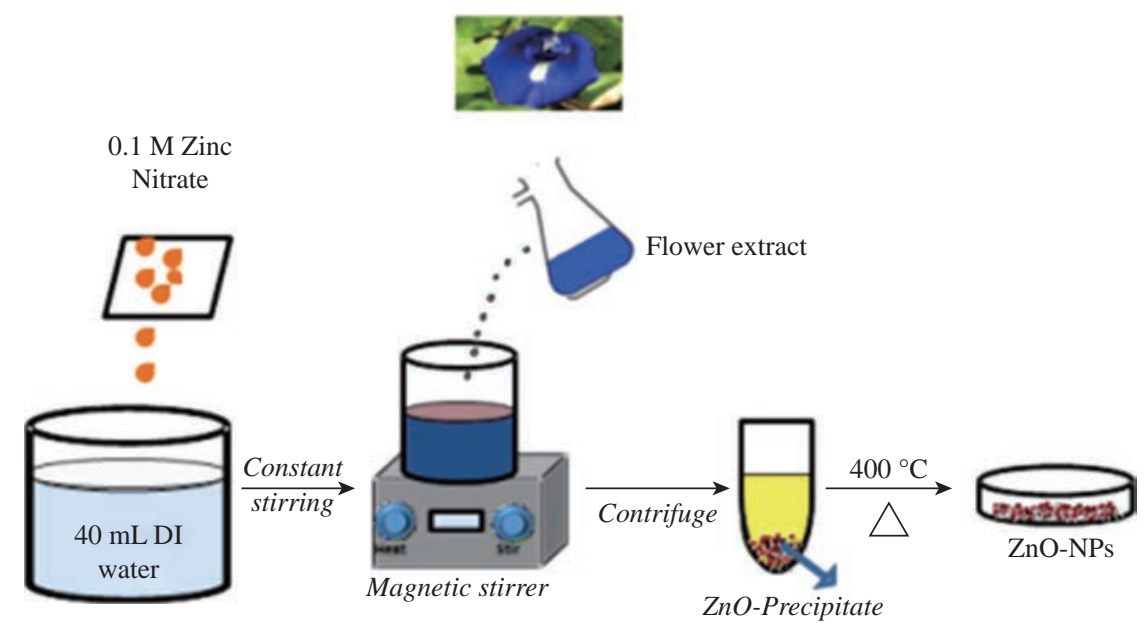

Fig. 1 Biosynthesis of ZnO NPs using Clitoria ternatea flower extract. 

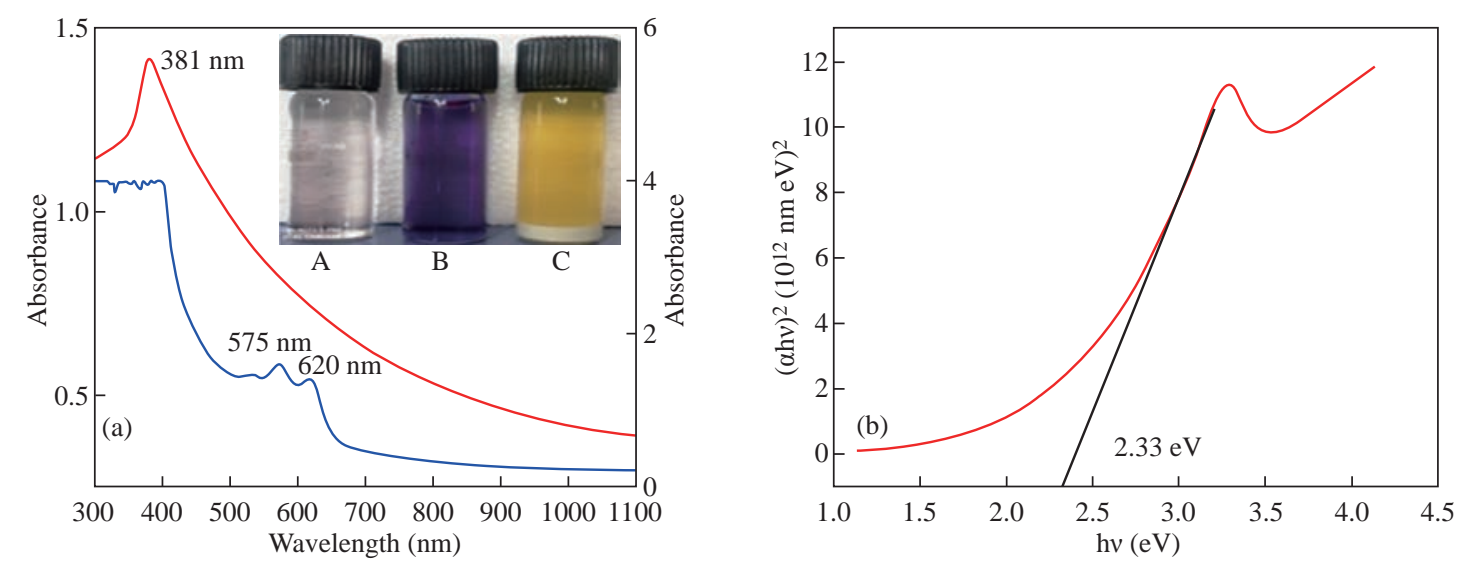

Fig. 2 (a) UV-visible spectra of Clitoria ternatea flower extract and ZnO NPs; (inset). A Zinc nitrate solution B Flower extract C ZnO NPs. (b) Tauc plot for ZnO NPs.

samples. The wells on the agar plates were prepared by punching with sterile micropipette tips. The wells were filled up with $50 \mu \mathrm{L}$ of the samples of different concentrations. The plates were then incubated at 37 ${ }^{\circ} \mathrm{C}$ for $24 \mathrm{~h}$. After incubation, the diameter (in $\mathrm{mm}$ ) of the areas that illustrated bacterial growth inhibition by the samples was measured.

\section{Characterization techniques}

The UV-visible absorption spectrum of the $\mathrm{ZnO}$ NPs was determined using (UV-Vis DRS) Perkin Elmer Lambda 25 spectrometer (JASCO V650). Absorbance spectra of the sample were recorded in wavelength range of 300-1100 nm. The FT-IR spectrum was recorded by using a Schimadzu IR Affinity $1 \mathrm{~S}$ series spectrophotometer in the range of $400-4500 \mathrm{~cm}^{-1}$. XRD pattern was obtained using Rigaku X-ray diffractometer with $\mathrm{Cu}-\mathrm{K} \alpha$ radiation $(\lambda$ $=1.5406 \AA$ ) and scanning angle $2 \theta$ over the range of $20^{\circ}-80^{\circ}$ at room temperature. The size distribution and zeta potential values were obtained using Dynamic Light Scattering (DLS) measurements carried out in a Zetasizer nanoseries (Malvern) instrument. The Surface morphology of the ZnO-NPs was studied using Field Emission Scanning Electron Microscope (FESEM) equipped with an EDAX, JEOL JEM 6390, Japan and Transmission Electron Microscope (TEM) JEOL JEM 2100 HRTEM.

\section{Results and discussion UV-visible spectroscopy}

The flower extract of Clitoria ternatea was added to the aqueous zinc nitrate solution which changes colour from violet to yellow colour indicating the formation of ZnO NPs. The UV-visible absorption spectrum of the biosynthesized ZnO NPs and the flower extract of Clitoria ternatea are shown in Fig. 2(a). The right $\mathrm{y}$-axis corresponds to the absorbance of $\mathrm{ZnO}$ while the left $y$-axis corresponds to that of the flower extract. The UV-visible absorption spectrum of the biosynthesized $\mathrm{ZnO}$ NPs showed a maximum absorption peak $(\lambda)$ at $381 \mathrm{~nm}$. The higher absorbance at 575 and $620 \mathrm{~nm}$ of the flower extract is attributed to the anthocyanin in the extract.

Further, Tauc's plot approach has been employed to elucidate the bandgap (Eg) of $\mathrm{ZnO}$ NPs according to the equation

$\alpha \mathrm{h} v=\mathrm{A}\left(\mathrm{h} v-\mathrm{E}_{\mathrm{g}}\right)^{\mathrm{n} / 2}$

where, $\alpha$ is the absorption coefficient, hv denotes the incident photon energy, $\mathrm{A}$ is a proportionality constant and $\mathrm{n}$ determine the nature of electronic transition. $\mathrm{n}$ is 0.5 and 2 for direct and indirect transitions, espectively. The plot of $(\alpha h v)^{2}$ against photon energy (hv) of the $\mathrm{ZnO}$ NPs gave a straight line and the optical band gap $\left(E_{g}\right)$ of the biosynthesized ZnO NPs was found to be $2.33 \mathrm{eV}$ (Fig. 2(b)) [22,23].

\section{FTIR analysis}

The FTIR spectra of Clitoria ternatea flower extract and $\mathrm{ZnO}$ NPs are shown in Fig. 3. In the flower extract, the broad stretching vibration observed at $3317 \mathrm{~cm}^{-1}$ is $\mathrm{O}-\mathrm{H}$ alcohol groups and phenolic compounds [24]. The peak at $2978 \mathrm{~cm}^{-1}$ is attributed to the aliphatic C$\mathrm{H}$ groups. A strong absorbance observed at $1635 \mathrm{~cm}^{-1}$ indicates the aromatic bending of $\mathrm{C}=\mathrm{C}$ and $\mathrm{C}=\mathrm{O}$ bonds present in the aromatic ring of the phenolic compounds [25]. The smaller peaks observed at 555 and $478 \mathrm{~cm}^{-1}$ are also assigned to the aromatic bending vibration of $\mathrm{C}-\mathrm{H}$ groups. The broad peaks at 2357 and $2360 \mathrm{~cm}^{-1}$, for $\mathrm{ZnO}$ and flower extract, respectively correspond to the asymmetric stretching of $\mathrm{CO}_{2}$ molecules [26]. The 




Fig. 3 FTIR spectra of ZnO NPs and Clitoria ternatea flower extract.

peaks observed at 1381 and $1382 \mathrm{~cm}^{-1}$ corresponding to the $\mathrm{C}-\mathrm{O}-\mathrm{H}[27]$. The metal-oxygen $(\mathrm{Zn}-\mathrm{O})$ stretching is observed between 493 and $424 \mathrm{~cm}^{-1}$. Thus, it can be concluded that the functional groups with $\mathrm{O}-\mathrm{H}$ and $\mathrm{C}=\mathrm{O}$ present in the Clitoria ternatea flower extract aid in the capping, reduction and stabilization agent of biosynthesized ZnO NPs [15,28].

\section{$\mathrm{X}$-ray diffraction analysis}

The XRD pattern of the biosynthesized ZnO NPs is shown in Fig. 4. The peaks were identified at $31.81^{\circ}$, $34.46^{\circ}, 36.29^{\circ}, 47.59^{\circ}, 56.65^{\circ}, 62.92^{\circ}$, and $68.01^{\circ}$ are associated with the (100) (002) (101) (102) (110) (103) and (112) planes of the hexagonal wurtzite structure of $\mathrm{ZnO}$ and is in good agreement with JCPDS (76-641). The sharp peaks revealed the crystalline nature and the absence of other peaks reveals the pure phase of the biosynthesized ZnO NPs. The average crystallite size (d) was calculated using the Scherrer Equation (2)

$\mathrm{d}=K \lambda /(\beta \cos \theta)$

where $K$ is the Scherrer constant that takes the value 0.9 ,



Fig. 4 XRD Pattern of $\mathrm{ZnO}$ NPs. $\lambda$ is the $\mathrm{X}$-ray wavelength, $\beta$ is the full width at half maximum (FWHM) of the diffraction peak and $\theta$ is the diffraction angle. The XRD pattern showed an average crystallite size of $18 \mathrm{~nm}$ [25].

\section{Dynamic light scattering (DLS)}

The average particle size determined by DLS is $102.5 \mathrm{~nm}$ as shown in Fig. 5(a), which is larger than the sizes observed in XRD and TEM. The Zeta potential value between $-30 \mathrm{mV}$ to $+30 \mathrm{mV}$ shows the moderate stable nature of any colloidal solution. Fig. 5(b), showed ZnO NPs indicates the negative zeta potential value of $-14.5 \mathrm{mV}$. The larger particle size and lower value of zeta potential further confirmed that the particles were agglomerate as a result of the electrostatic forces, weak van der Waalsinteraction and primary particles held by very strong chemical bonds [25, 29].


Fig. 5 (a) Size distribution and (b) Zeta potential of ZnO NPs

\section{FESEM analysis}

Surface morphology of the ZnO NPs was studied using Field Emission Scanning Electron Microscope (FESEM) analysis. It was observed that $\mathrm{ZnO}$ NPs are partially spherical and well distributed withagglomerated is shown in Fig. 6(a) \& (b). The agglomeration depends on van der Waal forces, electrostatic fields, sampling preparation, reactants attention and hydrophobic magnetism. This result is 

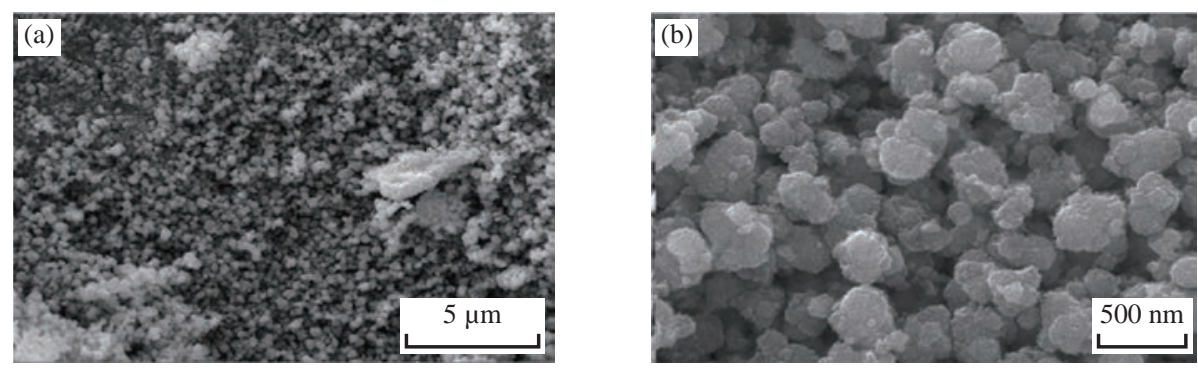

Fig. 6 FESEM images of ZnO NPs at different magnifications.

in close concordance with the previous findings and further corroborated by DLS studies (102.5 nm) [25].

\section{HR -TEM analysis}

The HRTEM images of ZnO NPs at different magnification (50 and $100 \mathrm{~nm}$ ) are shown in Fig. 7(a) \& (b). The images revealed that the particles were agglomerated and roughly spherical in shape. The selected area diffraction (SAED) pattern is shown in Fig. 7(c). The observed diffraction rings with concentric circles confirmed the crystalline nature of $\mathrm{ZnO}$ NPs which is in good agreement with the XRD results [24]. The average size of the ZnO NPs calculated from HRTEM images was found to be 41 nm. The particle size distribution is shown by the histogram in Fig. 7(d). EDX spectrum confirmed the presence of both $\mathrm{Zn}$ and $\mathrm{O}$ elements as shown in Fig. 7(e). The ZnO NPs was composed of $79.95 \%$ of zinc and $1.02 \%$ of oxygen. Furthermore, the atomic percent of zinc was found to be $77.11 \%$ and oxygen as $4.02 \%$.

\section{Antibacterial activity}

The antibacterial activity of the biosynthesized $\mathrm{ZnO}$ NPs was tested against $E$. coli and $S$. aureus bacteria using well diffusion method. The varied concentration of ZnO NPs (50, 100 and $200 \mu \mathrm{g} / \mathrm{mL}$ ) and the corresponding zones of inhibition $(\mathrm{mm})$ are shown in Fig. 8 and in Table 1. It was noticed that the biosynthesized ZnO NPs were more efficient over E. coli $(11 \mathrm{~mm})$ than the S.aureus $(10 \mathrm{~mm})$ bacteria. Normally, the antibacterial activity of ZnO NPs depends upon the particle size, shape, surface volume, larger band gap, biomolecules interaction and reaction and reactive oxygen species (ROS). The ZnO NPs produce ROS which stimulates the cellular oxidative metabolism and play an important role in the bacterial wall tearing down. The biomolecules that interact with the bacterial membrane causes the membrane to
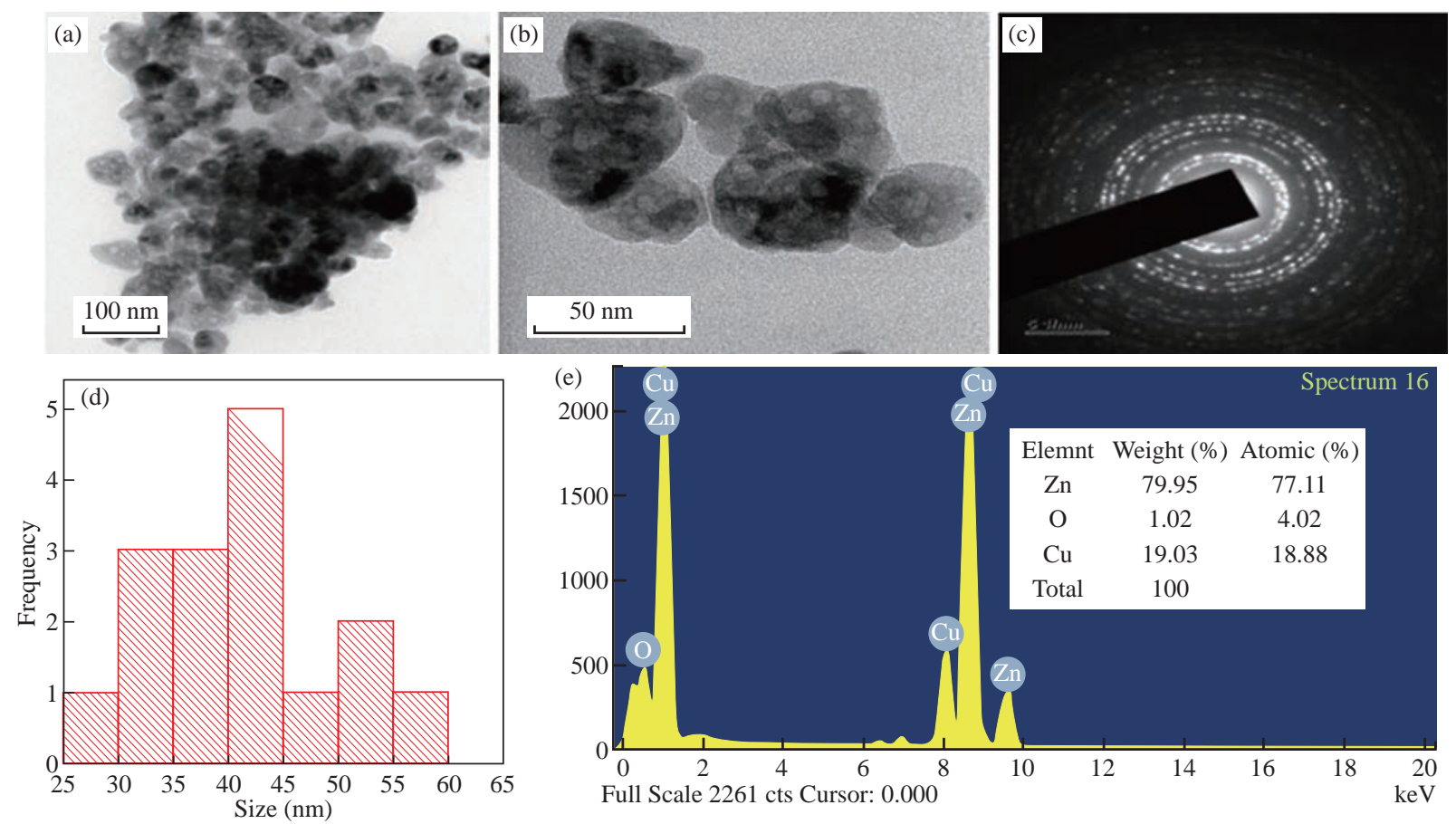

Fig. 7 HRTEM images of biosynthesized ZnO NPs at magnifications of (a) $100 \mathrm{~nm}$, (b) $50 \mathrm{~nm}$, (c) SAED pattern, (d) size distribution and (e) EDX spectrum. 

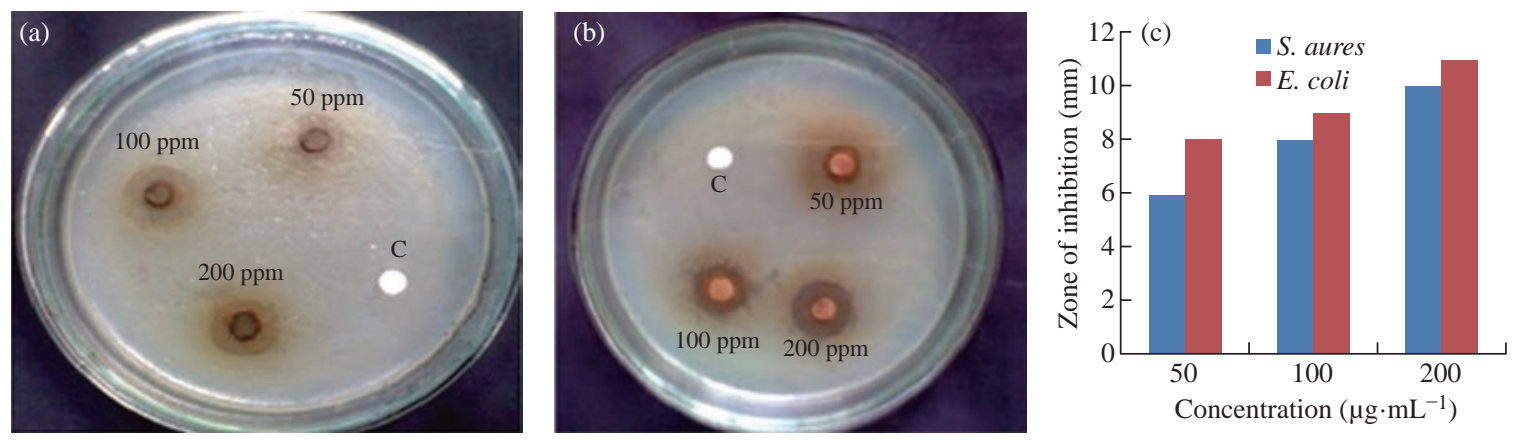

Fig. 8 Antibacterial activity of biosynthesized ZnO NPs against (a) S. aureus and (b) E. coli. (c) Antibacterial activity at different concentrations.

Table 1 Zone of inhibition for (a) E. coli and (b) S. aureus under different concentrations

\begin{tabular}{cccc}
\hline \multirow{2}{*}{ Microorganism } & \multicolumn{3}{c}{ Zone of Inhibition in (mm) } \\
\cline { 2 - 4 } & $50 \mu \mathrm{g} / \mathrm{mL}$ & $100 \mu \mathrm{g} / \mathrm{mL}$ & $200 \mu \mathrm{g} / \mathrm{mL}$ \\
\hline S. aureus & 6 & 8 & 10 \\
E. coli & 8 & 9 & 11 \\
\hline
\end{tabular}

collapse and rupture, resulting in bacterial cytoplasm destruction [30]. Interestingly, the ZnO NPs reveals inhibition activity against both tested bacteria but better efficiency was observed against gram-negative bacteria. The smaller crystallite size $18 \mathrm{~nm}$ and particle size $41 \mathrm{~nm}$ enables theZnO NPs to interact with the bacterial surface and enter inside the cell thereby exhibiting an outstanding bactericidal mechanism [31].

\section{Conclusions}

In conclusion, we report the biosynthesis of $\mathrm{ZnO}$ NPs using Clitoria ternatea flower extract and its antibacterial activity against $E$. coli and $S$. aureus. The flower extract of Clitoria ternatea showed excellent potential as capping and reducing agents in the formation of ZnO NPs. The UV and FTIR spectra results confirmed the formation of $\mathrm{ZnO} N P s$, with an optical band gap of $3.25 \mathrm{eV}$. The XRD results revealed a hexagonal wurtzite structure with an average particle size of $18 \mathrm{~nm}$. The crystalline nature of ZnO NPs was verified from the SAED pattern and XRD peaks. The FESEM image indicates that nanoparticles were agglomerated with a roughly spherical shape. Zeta potential study reveals a negative charge on the surface of ZnO NPs. The particle size was determined by TEM analysis was $41 \mathrm{~nm}$ and the EDX spectrum confirmed the presence of $\mathrm{Zn}$ and $\mathrm{O}$ elements. The obtained antibacterial activity results suggest that ZnO NPs could be useful in various bacteria-based biomedical applications.

\section{Acknowledgements}

Author SP sincerely acknowledges the Department of Nanoscience and Technology, Sri Ramakrishna Engineering College-Coimbatore, for providing UV, FTIR, XRD analysis and DST-FIST lab facilities, and Hindusthan College of Engineering and Technology, Coimbatore, for providing technical support.

\section{Conflict of Interests}

The authors declare that no competing interest exists.

\section{References}

[1] N.H.A Nguyen, V.V.T Padil, V.I. Slaveykova, et al., Green Synthesis of Metal and Metal Oxide Nanoparticles and Their Effect on the Unicellular Alga Chlamydomonas reinhardtii. Nanoscale Res. Lett, 2018, 13: 159.

[2] S. Stankic, S. Suman, F. Haque, J. Vidic, Pure and multi metal oxide nanoparticles: synthesis, antibacterial and cytotoxic properties. J Nanobiotechnol, 2016, 14: 73.

[3] N. Tripathy, D. Kim, Metal oxide modified ZnO nanomaterials for biosensor applications. Nano Converg, 2018, 5:27.

[4] A. Czyżowska, A. Barbasz, A review: zinc oxide nanoparticles-friends or enemies? Int. J. Environ. Health Res, 2020,10: 1-17.

[5] D. M Cruz, E. Mostafavi, A.Vernet-Crua, et al., Green nanotechnology-based zinc oxide $(\mathrm{ZnO})$ nanomaterials for biomedical applications: a review. J. Phys. Mater, 2020, 3 : 034005.

[6] H. Agarwal, S. Kumar, S. Rajeshkumar, A review on green synthesis of zinc oxide nanoparticles - An ecofriendly approach. Resource-Efficient Technologies, 2017, 3: 406-413.

[7] R.E Adam, G. Pozina, M. Willander, O. Nur, Synthesis of $\mathrm{ZnO}$ nanoparticles by co-precipitation method for solar driven photodegradation of Congo red dye at different pH. Photonics and Nanostructures - Fundam. Appl, 2018, 32: $11-18$.

[8] D. Bharti, A.V Bharati, Synthesis of $\mathrm{ZnO}$ nanoparticles using a hydrothermal method and a study its optical activity. Luminescence, 2016, 32 (3): 317-320.

[9] M.F. Khan, A. H Ansari, M. Hameedullah, et al., Sol- 
gel synthesis of thorn-like $\mathrm{ZnO}$ nanoparticles endorsing mechanical stirring effect and their antimicrobial activities: Potential role as nano-antibiotics. Sci Rep, 2016, 6: 27689.

[10] A. Jose, K.R.S. Devi, D. Pinheiro, et al., Electrochemical synthesis, photodegradation and antibacterial properties of PEG capped zinc oxide nanoparticles. J. Photochem. Photobiol. B, 2018,187: 25-34.

[11] T. Ghoshal, S. Biswas, M. Paul, et al., Synthesis of ZnO Nanoparticles by Solvothermal Method and Their Ammonia Sensing Properties. J. Nanosci. Nanotechnol, 2009, 9: 5973-5980.

[12] M. Hasanpoor, M. Aliofkhazraei, H. Delavari, Microwave-assisted synthesis of zinc oxide nanoparticles. Procedia Material Science, 2015, 11: 320-325.

[13] K. Ali, S. Dwivedi, A. Azam, et al., Aloe vera extract functionalized zinc oxide nanoparticles as nanoantibiotics against multi-drug resistant clinical bacterial isolates. J. Colloid Interface Sci, 2016, 472: 145-156.

[14] K. Elumalai, S. Velmurugan, S. Ravi, et al., Green synthesis of Zinc oxide nanoparticles using Moringa oleifera leaf extract and evaluation of its antimicrobial activity. Spectrochim. Acta A, 2015, 143: 158-164.

[15] N. Senthilkumar, E. NandhaKumar, P. Priya, et al., Synthesis, Anti-bacterial, Anti-arthritic, Anti-oxidant and In-vitro Cytotoxicity Activities of ZnO Nanoparticles Using Leaf Extract of Tectona Grandis (L.). New J. Chem, 2017, 41: 10347-10356.

[16] G. Sathishkumar, Rajkuberan, K. Manikandan, et al., Facile biosynthesis of antimicrobial zinc oxide $(\mathrm{ZnO})$ nanoflakes using leaf extract of Couroupita guianensis, Aubl. Mater. Lett, 2017, 188: 383-386.

[17] N. Bala, S. Saha, M. Chakraborty, et al., Green synthesis of zinc oxide nanoparticles using Hibiscus subdariffa leaf extract: Effect of temperature on synthesis, anti-bacterial activity and antidiabetic activity. RSC Adv, 2015, 5: 4993-5003.

[18] M. Naseer, U. Aslam, B. Khalid, et al., Green route to synthesize Zinc oxide nanoparticles using leaf extracts of Cassia fistula and Melia azadarach and their antibacterial potential. Sci Rep, 2020, 10: 9055.

[19] D. Suresh, R.M Shobharani, P.C. Nethravathi, et al., Artocarpus gomezianus aided green synthesis of $\mathrm{ZnO}$ nanoparticles: Luminescence, Photocatalytic and Antioxidant Properties. Spectrochim. Acta A, 2015, 141: 128-134.

[20] K. Elumalai, S. Velmurugan, S. Ravi, et al., Bio-approach: Plant mediated synthesis of $\mathrm{ZnO}$ nanoparticles and their catalytic reduction of methylene blue and antimicrobial activity. Adv Powder Tech, 2015, 26 (6): 1639-1651.

[21] N. Jamil, F. Paee, Antimicrobial Activity from Leaf, Flower, Stem, and Root of Clitoria ternatea - A Review. AIP Conf. Proc, 2018, 2002: 020044.
[22] N.A. Ludin, M.A.M. Al-Alwani, A. BMohamad, et al., Utilization of Natural Dyes from Zingiber officinale Leaves and Clitoria ternatea Flowers to Prepare New Photosensitisers for Dye-Sensitised Solar Cells. Int. J. Electrochem. Sci, 2018, 13: 7451-7465.

[23] K. Rambabu, G. Bharath, F. Banat, et al., Green synthesis of zinc oxide nanoparticles using Phoenix dactylifera waste as bioreductant for effective dye degradation and antibacterial performance in wastewater treatment. J. Hazard. Mater, 2021, 402: 123560.

[24] T. Safawo, B. Sandeep, S. Pola, et al., Synthesis and characterization of zinc oxide nanoparticles using tuber extract of anchote (Coccinia abyssinica (Lam.) Cong.) for antimicrobial and antioxidant activity assessment. OpenNano, 2018, 3: 56-63.

[25] M. Khan, P. Ware, N. Shimpi, Synthesis of ZnO nanoparticles using peels of Passiflora foetida and study of its activity as an efficient catalyst for the degradation of hazardous organic dye. SN Applied Sciences, 2020, 3: 528.

[26] M.D McCluskey, A.D. Lalonde, M.G.Norton, et al., Infrared spectroscopy of $\mathrm{ZnO}$ nanoparticles containing $\mathrm{CO}_{2}$ impurities. Appl. Phy. Lett. 2005, 86: 073111.

[27] S.O. Ogunyemi, Y. Abdallah, M. Zhang, et al., Green synthesis of zinc oxide nanoparticles using different plant extracts and their antibacterial activity against Xanthomonas oryzae pv. oryzae. Artif Cells Nanomed Biotechnol, 2019, 47 (1): 341-352.

[28] D. Sharma, R. Jha,Analysis of structural, optical and magnetic properties of Fe/Co co-doped $\mathrm{ZnO}$ nanocrystals. Ceram. Int. 2017, 43: 8488-8496.

[29] D. Cao, S. Gong, X. Shu, et al., Preparation of $\mathrm{ZnO}$ Nanoparticles with High Dispersibility Based on Oriented Attachment (OA) Process. Nanoscale Res. Lett, 2019, 14: 210.

[30] M.D Jayappa, C.K. Ramaiah, M.A.P. Kumar, et al., Green synthesis of zinc oxide nanoparticles from the leaf, stem and in vitro grown callus of Mussaenda frondosa L.: characterization and their applications. Appl. Nanosci, 2020, 10: 3057-3074.

[31] Y.N Slavin, J. Asnis, U.O Hafeli, et al., Metal nanoparticles: understanding the mechanisms behind antibacterial activity. J. Nanobiotechnol, 2017, 15: 65.

Copyright $\odot$ Selvaraj Prabhu, Daniel Thangadurai Thangaian, and Palaniswamy Vijai Bharathy. This is an open-access article distributed under the terms of the Creative Commons Attribution License, which permits unrestricted use, distribution, and reproduction in any medium, provided the original author and source are credited. 